Discussion Paper No. 07-086

\title{
Durable Goods, Innovation and Network Externalities
}

Daniel Cerquera

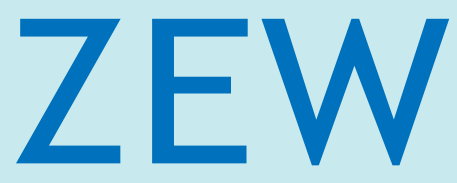

Zentrum für Europäische Wirtschaftsforschung $\mathrm{GmbH}$

Centre for European

Economic Research 
Discussion Paper No. 07-086

\title{
Durable Goods, Innovation and Network Externalities
}

\author{
Daniel Cerquera
}

Download this ZEW Discussion Paper from our ftp server:

ftp://ftp.zew.de/pub/zew-docs/dp/dp07086.pdf

Die Discussion Papers dienen einer möglichst schnellen Verbreitung von neueren Forschungsarbeiten des ZEW. Die Beiträge liegen in alleiniger Verantwortung der Autoren und stellen nicht notwendigerweise die Meinung des ZEW dar.

Discussion Papers are intended to make results of ZEW research promptly available to other economists in order to encourage discussion and suggestions for revisions. The authors are solely responsible for the contents which do not necessarily represent the opinion of the ZEW. 


\section{Non-technical summary}

An industry exhibits network externalities when the benefit that consumers enjoy from purchasing one or several of its goods depends on the number of other consumers that use the same and/or compatible products (e.g. software, operating systems, consumer electronics, telecommunications, etc.). The goods produced in these industries (i.e. network goods) are characterized by two features closely related, durability and rapid technological progress. Durability implies that these goods tend to "wear out" not as a result of physical deterioration, but as a consequence of technical obsolescence; a feature due to technological progress. For example, a given software can be functional for a long time. However, the utility derived by its use tends to be dissipated due to new developments that are more closely related to consumers' needs and tastes.

The economic consequences of durability are profound. Specifically, durability implies that firms' strategies attempt at extracting consumers' current and future surplus. However, firms' long-term strategies that affect consumers' future surplus and future profits (e.g. R\&D investments) might conflict with short-term strategies that determine current profits (e.g. prices). For example, by innovating too much, a firm might reduce the willingness to pay (i.e. demand) of current consumers realizing that the offered good will rapidly become obsolete.

This paper analyzes a stylized network industry where durability and technological progress are considered together. In particular, the paper proposes a model of R\&D competition between an incumbent and a potential entrant and considers the implications of the durability of network goods (i.e. conflicts between firms' short-term and long-term strategies). The main objective is to isolate the role of network externalities and analyze the social efficiency of the R\&D incentives of the firms in this industry.

The paper shows three main results. First, the threat of entry eliminates the conflict, due to durability, between short-term pricing and R\&D investment of a monopolist. This result follows from the role that R\&D incentives play in deterring entry. Second, the levels of R\&D determined by market outcome might differ from the socially optimal levels. In particular, a potential entrant always over-invests and an established incumbent might exhibit higher, lower or equal R\&D levels in comparison with the social optimum. And third, the extent of network externalities is the crucial parameter in the efficiency (i.e. comparison with the socially optimal solution) of the incumbent R\&D level. 


\title{
Durable Goods, Innovation and Network Externalities
}

\author{
Daniel CERQUERA*
}

December 29, 2007

\begin{abstract}
We develop a model of R\&D competition between an incumbent and a potential entrant with network externalities and durable goods. We show that the threat of entry eliminates the commitment problem that an incumbent may face in its $R \& D$ decision due to the goods' durability. Moreover, a potential entrant over-invests in $R \& D$ and an established incumbent might exhibit higher, equal or lower $R \& D$ investments in comparison with the social optimum. In our model, the incumbent's commitment problem and the efficiency of its R\&D level are determined by the extent of the network externalities.
\end{abstract}

Keywords: Network externalities, Durable Goods, Innovation, Imperfect Competition. JEL Classification: D21, D85, L13, O31.

\footnotetext{
*cerquera@zew.de. Centre for European Economic Research (ZEW), Mannheim, Germany. Research Group Information and Communication Technologies. I would like to thank Irene Bertschek, Jay P. Choi, Toker Doganoglu, Stefan Mittnik, Gal Oestreicher-Singer, Monika Schnitzer and Sven Rady for helpful comments and suggestions, as well as seminar participants at the University of Munich and the 2006 European Economic Association Annual Congress in Vienna, the 2006 Latin American and Caribbean Economic Association Annual Meeting in Mexico City, the Telecom Paris 2007 Conference on the Economics of ICT and the 2007 European Association of Research in Industrial Economics Annual Congress in Valencia. Part of this research was completed at the Center for Information and Network Economics at the University of Munich. Generous financial support from Volkswagen Stiftung and the Munich Graduate School of Economics made this research possible. All errors are mine.
} 


\section{Introduction}

An industry exhibits network externalities when the benefit that consumers enjoy from purchasing one or several of its goods depends on the number of other consumers that use the same and/or compatible products. For the firms in those sectors (e.g. software, telecommunications, consumer electronics, etc.), the presence of network externalities implies that the attractivenss of their products is a function of their quality-adjusted prices and the potential benefit attached to their expected network sizes (i.e. installed bases) ${ }^{1}$

Those products (i.e. network goods) tend to be characterized by two features closely related. Durability and rapid technological progress ${ }^{2}$ Durability implies that network goods tend to "wear out" not as a result of physical deterioration, but as a consequence of technical obsolescence; a feature due to technological progress. For example, a given software (or mobile phone, or video game, etc.) can be functional for a long time. However, the utility derived by its use tends to be dissipated due to new (and actually very frequent) developments that are more closely related to consumers' needs and tastes.

This paper considers a stylized network industry where these two features, durability and technological progress, are analyzed together. In particular, we propose a model of R\&D competition between an incumbent and a potential entrant and consider the implications of the durability of network goods. Our main objective is to isolate the role of network externalities and analyze the social efficiency of the R\&D incentives of the firms in this industry.

We depart from the current literature by considering, simultaneously, an oligopolistic setup, endogenous R\&D processes and durable goods. Therefore, this paper is not only closely related to the literature on durable goods and to the literature on technological progress in network industries, but represents a first step in bridge them together.

The economic literature has highlighted the role that durability plays in the evolution of a market dominated by a monopolist. In particular, after serving the current market, the monopolist is tempted to reduce its price to attract the portion of the market that did not buy initially. However, rational consumers anticipate this behavior and, specially

\footnotetext{
${ }^{1}$ See Katz and Shapiro $(1985,1986)$ and Farrel and Saloner $(1985,1986)$ for seminal treatments, and Katz and Shapiro (1994) and Economides (1996) for surveys on network markets.

${ }^{2}$ See Katz and Shapiro (1999) for an informal analysis of antitrust in software markets, where these two characteristics are explicitly considered.
} 
those with low valuations of the offered good, will wait until the price is reduced. As a consequence, a commitment of "no future price reductions" would increase the monopolist's profits. The fact that in the absence of commitment the monopolist may act against his own profitability implies a "time-inconsistency" problem (i.e. choices that maximize current profitability might not maximize overall profitability).

This situation was first discussed by Coase (1972) and has been labelled as the "Coase Conjecture" 3 Since its formulation, the Coase Conjecture has been theoretically developed in several papers that evaluate the robustness of the basic observation 4

The problem is that the monopolist's future actions provide competition for the company in the current market.5 As has been suggested in the literature, if the monopolist is able to lease the good, distort technology or implement buy back procedures then more profit can be extracted from the market since these strategies restrict the aftermarket 6 In other circumstances, the monopolist might have an incentive to reduce durability or make the good obsolete after a period of time 7 The existing analysis of durability in the presence of network externalities has intended, as the main literature on durability, to verify the validity of the Coase Conjecture. ${ }^{8}$

However, the implications of durability are much broader than the pricing commitment problem considered in the analysis of the Coase Conjecture. In particular, the result that a monopolist in the absence of commitment may affect its own overall profitability applies in several contexts. In fact, as pointed out by Waldman (2003), any present and future action that affects the future (relative) value of the monopolist's used goods might be subject to the "time-inconsistency" described above. One leading case of such actions is a firm's R\&D expenditures which, by definition, affect the (relative) value of used (or previously sold) goods $?^{9}$

In the presence of network externalities, the similar analysis of introduction of new

\footnotetext{
${ }^{3}$ Strictly, the Coase Conjecture refers to a limiting case. It states that in the absence of commitment and if the monopolist may adjust its prices frequently enough, the successive price reductions lead to marginal cost pricing and the subsequent loss of market power.

${ }^{4}$ See, for example, Bagnoli, Salant and Swierzbinski (1989), Bulow (1982), Gul, Sonnenschein and Wilson (1986), and Stokey (1981).

${ }^{5}$ The price of a durable good attempts to extract current and future surplus, however, future surplus depends on future actions that are not realized when the price is set.

${ }^{6}$ See Fudenberg and Tirole (1998), Kahn (1986) and Waldman (1997).

${ }^{7}$ See Bulow (1986), Hendel and Lizzeri (1999), Rust (1986) and Waldman (1993), Grout and Park (2005).

${ }^{8}$ See Bensaid and Lesne (1996), Cabral et al. (1999) and Mason (2000).

${ }^{9}$ See Waldman (1996), Fishman and Rob (2000) and Nahm (2004).
} 
durable goods has been analyzed.10 However, this literature is focused on a monopolistic setup and considers the production of new technologies as exogenous. Hence, and to the best of our knowledge, there is no analysis that considers explicitly the process of endogenous R\&D processes in the presence of network externalities and durable goods.

The paper presented by Ellison and Fudenberg (2000) is the closest to ours and is actually our departure point. In that paper, the authors consider a monopolist that operates in a two-period framework and produces durable network goods. In the first period the monopolist produces a good with a given low quality and, subsequently, has the choice of introducing an improved version in the second period. Network externalities play a role because the improvement of the old good implies backward compatibility. That is, consumers of the new good enjoy network benefits from the entire population, while consumers of the old good only enjoy network benefits from consumers of the same $\operatorname{good} 11$

In their model, there is an inflow of new consumers in the second period and, with consumer homogeneity, the paper shows that the monopolist has the incentive to introduce the improved good, even though the monopolist's overall profits (and social surplus) is reduced. That is, in the absence of commitment the monopolist's choice that maximizes current (second period) profits does not maximize overall profitability.

We present a model that extends that of Ellison and Fudenberg (2000) by introducing and endogenous $R \& D$ process in the production of the new technology, and consider the role of a potential entrant. We show results not present in the Ellison and Fudenberg (2000) analysis. In particular, we consider a two-period framework with an incumbent, a potential entrant and an inflow of new consumers. Consumers are homogeneous and participate in a market with durable network goods.

In the first period, there is a first group of consumers that buy a network good from the established incumbent. Before the second period starts, a potential entrant appears in the market and, jointly with the incumbent, decides on an investment level that will allow him to compete in the second period. This R\&D process is stochastic. By investing a certain amount, both firms, incumbent and entrant, determine the probability that in the second period they are able to produce a new product that is quality-improved relative to the existing good produced by the incumbent. Conditional on the success or failure

\footnotetext{
${ }^{10}$ See Choi (1994) and Ellison and Fudenberg (2000).

${ }^{11} \mathrm{~A}$ case of this situation was evidenced by the launch of Microsoft Word 97. Consumers of Word97 were fully compatible with consumers of Word95 but the opposite did not hold.
} 
of the innovation process, both firms compete in price in the second period when a new group of consumers arrive.

We analyze the incentives to innovate for both firms, we compare it to the social optimum and investigate the role of the network externalities. With our simplified approach, we are able to isolate the impact of network externalities and reach three main results 12

First, the threat of entry reverses the commitment problem that a monopolist (without such threat) may face in its R\&D decision given good durability. This result is not present in the current literature and follows from the role that $R \& D$ incentives play in deterring entry. In our case, the monopolist's commitment problem arises only due to the presence of network externalities.

Second, the levels of $R \& D$ determined by market outcome might differ from the socially optimal levels. In particular, a potential entrant always over-invests (as an entry strategy) and an established incumbent might exhibit higher, lower or equal R\&D levels in comparison with the social optimum. This result suggests that successful entry takes place too often in comparison with the social optimum.

And third, the extent of network externalities is the crucial parameter in the efficiency of the incumbent $\mathrm{R} \& \mathrm{D}$ level. In fact, it is only the presence of network externalities that permits, potentially, to the established incumbent to provide an efficient level of innovation. Without network externalities (or very low network effects), it is shown that the incumbent firm always under-invests in $\mathrm{R} \& \mathrm{D}$ efforts. This result sheds some light on the debate whether a dominant incumbent in a network industry provides sufficient innovation to the society.

The paper is organized as follows. The next section presents the model. Section 3 presents the analysis of its equilibrium. Section 4 computes the social optimum and compares it with the results of the market outcome. Finally, section 5 concludes and discusses some areas of further research.

\footnotetext{
${ }^{12}$ The robustness of these results with respect to the assumed functional forms is the objective of current work.
} 


\section{The Model}

We consider a model of a network industry with durable goods based on that of Ellison and Fudenberg (2000) ${ }^{13}$ There are two periods denoted by $t=1$ and $t=2$ with a group of homogeneous consumers arriving in each period. In period 1 there is a monopolist incumbent that is challenged in period 2 by a potential entrant. In period 2, firms compete in prices with quality differentiated products. Quality is determined through endogenous and stochastic R\&D processes carried out in period 1.

\subsection{Supply Side and R\&D Process}

In period 1, an incumbent monopolist, $I$, produces a durable network good with quality level $q_{1}$ (i.e. stand-alone value). The good lasts two periods after which it vanishes. We consider the case of product innovations where, subject to $R \& D$ expenditures, the incumbent might be able to produce a network good of better quality to be introduced in period 2. In our model, this process of innovation is carried out at the end of period 1. In addition, we assume that the outcome of the $R \& D$ process is stochastic with two possible outcomes, success or failure. This outcome is realized at the beginning of period 2 .

In particular, we consider an R\&D process where the incumbent firm determines the probability $s_{I}$ that the innovation process is successful. Higher investments (i.e. higher probability of success) entail higher costs. These costs are summarized by means of a function $C\left(s_{I}\right)$ that is increasing in the probability of success $s_{I}$. For simplicity, we assume that $C\left(s_{I}\right)=\frac{a s_{I}^{2}}{2}$, where $a$ is a cost parameter.

In the case of success, the innovation is achieved and allows the incumbent firm to produce a "new" network good with quality $q_{2}$ in period 2 , where $q_{2}=q_{1}+q_{\Delta}$ and $q_{\Delta}$ is the extent of the innovation. $q_{\Delta}$ is assumed to be constant and greater than zero. If the innovation process is unsuccessful, the incumbent produces in period 2 the same "old" good with low quality $q_{1}$. It is assumed that the achievement of the innovation do not preclude the incumbent to produce the "old" good in period 2.

In addition, we introduce a potential entrant, $E$, that intends to compete with the incumbent in period 2. In order to be able to enter the market, the potential entrant must

\footnotetext{
${ }^{13}$ We construct our model to make Ellison and Fudenberg (2000) a particular case of the one presented here. A more general version is work in progress.
} 
invest in R\&D to develop a network good. The entrant's innovation process takes place simultaneously with that of the incumbent firm. It is assumed, that the innovation process for the potential entrant is identical to the one of the incumbent firm. Therefore, the potential entrant must determine the probability $s_{E}$, that its innovation process succeeds. If so, the entrant is able to produce the "new" good with quality $q_{2}$ in period 2 . It is assumed that in the case of unsuccessful innovation, the entrant firm stays out of the market (i.e. it cannot produce the old quality network good).

As in Ellison and Fudenberg (2000), we assume that the network goods are backward compatible. That is, consumers of the new good enjoy network benefits from all users (i.e. users of new and old goods), while consumers of the old good only enjoy network benefits from consumers of the same good (e.g. Word97 vs. Word95) ${ }^{14}$

It is further assumed that the firms cannot change the quality of the goods once they are already produced. Marginal costs of production are independent of quality and set equal to zero. For simplicity the discount factor is equal among firms and normalized to 1.

\subsection{Demand Side and Expectation Formation Process}

The demand side represents the core of the model. In each period there is a group of $N_{t}$ homogeneous consumers arriving in the market and, for convenience, we normalize $N_{1}+N_{2}=1$. Consumers exhibit a per-period unitary demand for a network good and buy as soon as they reach the market. This implies that the $N_{1}$ consumers make purchase decisions in period 1 and in period 2. Given durability, this is not a trivial implication.

To see this, note that the price charged to the $N_{1}$ consumers in period 1 tries to extract period 1 and 2 surpluses (i.e. the good is durable). However, period 2 surplus is affected by the outcome of the R\&D processes, the prices of the two firms in period 2 and the $N_{1}$ and $N_{2}$ consumers' choices. Therefore, the willingness to pay of the $N_{1}$ consumers in period 1 depends on their beliefs on how the firms are going to behave in period 2. This gives rise to the commitment problem discussed in the introduction.

Consider first period 1. The first group of consumers, with size $N_{1}$, arrives at the beginning of period 1, finds only the incumbent's good and observes its price (to be

\footnotetext{
${ }^{14}$ Note that the assumption of backward compatibility implies that, conditional on successful innovation, the surplus offered by the new good is independent of the identity of the firm that produces it.
} 
derived below). We model utility by assuming that each consumer in $N_{1}$ derives a firstperiod benefit (gross of price) from buying from the incumbent firm given by $q_{1}+\alpha x-c$. In this expression, $q_{1}$ is the quality of the good, $\alpha$ is a parameter that measures the extent of the network benefits, $x$ is the number of users of compatible goods ${ }^{15}$ and $c$ is a cost of learning to use the network good. We introduce the following assumptions.

Assumption 1. $2 q_{1}>0 . N_{1}$ always consume the old good in period 1.

By introducing assumption 1, the model implies that even in the case where network benefits are equal to zero, first period consumers always consume. This assumption will allow us to analyze the model with very small (or non-existent) network benefits and compare the results with the case where network externalities are important without introducing discontinuities in the consumers' behavior.

Assumption 2. $q_{1}+\alpha N_{1}-c_{u}>0$. It is optimal for $N_{1}$ to consume in both periods.

The previous assumption 2 is introduced to avoid the possibility of $N_{1}$ consumers waiting to period 2 to consume 16 This assumption reduces the number of cases to be analyzed, and allows us to focus on the results we are interested in 17

Of course, the overall benefit enjoyed by consumers in $N_{1}$ also depends on period 2 choices to be explained below. Note that at the beginning of period 2, the outcome of the innovation process is realized depending on the investment decisions. Hence, there are four possible cases in period 2; no firm innovates; only the incumbent or only the entrant innovates; and both firms achieve the innovation.

Now consider period 2. When the $N_{1}$ consumers reach the beginning of period 2, they observe the outcome of the innovation process. If the innovation is achieved, the $N_{1}$ consumers evaluate the incremental utility from purchasing (i.e. upgrading to) the new generation of the good and decide accordingly 18 Therefore, they compare the benefit (gross of price) from the new good $q_{2}+\alpha\left(N_{2}+x\right)-c_{u}$ with the second-period benefit of staying with the old good $q_{1}+\alpha x . c_{u}$ is the cost of learning to use the new generation

\footnotetext{
${ }^{15}$ Note that given the homogeneity of the consumers $x=N_{1}$ in period 1 .

${ }^{16}$ In order to maintain the order of the exposition, the parameter $c_{u}$ (i.e. the cost of upgrading) is introduced below.

${ }^{17}$ See, for example, Choi and Thum (1998) for the analysis when consumers can wait to adopt a network good.

${ }^{18}$ Recall that for the $N_{1}$ consumers the identity of the firms that produces the new good in period 2 is irrelevant (footnote 14).
} 
(i.e. cost of upgrading). It is assumed that $c_{u}<c$. As common in models with network externalities, the equilibrium value of $x$ depends on the way consumers form expectations about other consumers behavior.

We assume that consumers are able to coordinate on the outcome that maximize their surplus (i.e. Pareto-Optimal coordination equilibrium) 19 In other words, consumers are able to coordinate on the choice that maximize joint surplus. Thus, they compare $q_{2}+\alpha-c_{u}$ with $q_{1}+\alpha N_{1}$ and, in consequence, the incremental utility from upgrading is given by $q_{\Delta}+\alpha N_{2}-c_{u}$. Hence, whenever $q_{\Delta}+\alpha N_{2}-c_{u}>0$ upgrade by the $N_{1}$ consumers takes place, otherwise the $N_{1}$ consumers do not buy the new good and stay with the old one. We denote this (candidate) price of upgrading as $p_{u}$.

In period 2, a second group of consumers with size $N_{2}$ arrives in the market. This group of consumers observes the outcome of the innovation process, observes prices (to be derived below) and makes purchase decisions. In particular, it is assumed that whenever the innovation is successful (either by the incumbent, the entrant or both) the $N_{2}$ consumers do not exhibit any preference for the old good produced by the incumbent. That is, the willingness to pay of $N_{2}$ consumers for the new generation of the good is equal to $q_{2}+\alpha-c{ }^{20}$ We denote this (candidate) price as $p_{n}$. Note that given the assumption of backward compatibility, consumers of the new good enjoy the full network benefits (i.e $\alpha x$ with $x=1)$.

In the case that the innovation does not take place (i.e. no firm innovates), the $N_{2}$ consumers decides for the old good with a willingness to pay equal to $q_{1}+\alpha-c$. We denote this (candidate) price as $p_{o}$. Therefore, analogous to Ellison and Fudenberg (2000), it is the choice of the $N_{1}$ consumers in period 2 that represents the most important part of the analysis.

In the next section we present the main results of the market outcome.

\section{Market Outcome}

In this section we consider the optimal pricing decisions and the two firms' private incentives to innovate. As a benchmark, we consider first the monopoly case. This analysis will

\footnotetext{
${ }^{19}$ See Katz and Shapiro (1986) and Farrell and Katz (2005).

${ }^{20}$ This assumption allows the incumbent monopolist to extract the full consumers surplus in the case without entry. Therefore, it permits us to conclude that any reduction in the monopolist's profit implies a reduction in social welfare.
} 
allow us to compare the present paper with the current literature, to analyze the impact of network externalities and highlight the main results we obtain in comparison with Ellison and Fudenberg (2000). Once the monopoly case is considered, we analyze the model where the incumbent monopolist faces the threat of entry. In both cases, we consider the commitment as well as the no commitment case given its role in the durability literature discussed in the introduction.

As has been widely highlighted in the literature, the no commitment case is equivalent to focus on the Subgame-Perfect Nash-Equilibrium (SPNE), and the commitment case corresponds to the Nash-Equilibrium (NE) of the global multi-stage game.

\subsection{A Monopoly Model}

In order to solve the monopoly model, we first solve for the period 2 demands, profits and price equilibria. Then, we turn to the investment decision at the end of period 1 and derive the commitment and the no commitment case.

\subsubsection{Second Period - Pricing Decision}

Before deriving the equilibrium prices conditional on the outcome of the R\&D process, it is important to note that the value of $p_{u}$ is critical to the analysis because it describes the situation where upgrade takes place.

Assumption 3. $p_{u}>0$. Whenever the new good is produced, it is optimal for $N_{1}$ to upgrade.

We focus on the analysis, unless otherwise noticed, for cases when assumption 3 holds. (i.e. upgrade is possible and optimal) and later on we present a brief discussion considering the case when assumption 3 does not hold.

Note that price competition depends on the outcome of the innovation process, therefore, there are two cases to consider according to the success or failure of the monopolist's innovation process.

Monopolist does not innovate. In this case, the monopolist still produces the old good with quality $q_{1}$ in period 2 . As explained before, the $N_{1}$ consumers do not make any purchase decision (they already have the only existing good) and the $N_{2}$ consumers buy the old good if the price is less or equal to the maximum surplus offered by the good 


\begin{tabular}{|c|c|c|}
\hline & $\begin{array}{c}\text { Monopolist } \\
\text { does not innovate }\end{array}$ & $\begin{array}{c}\text { Monopolist } \\
\text { does innovate }\end{array}$ \\
\hline \hline $\begin{array}{c}\text { Monopolist's } \\
\text { Prices }\end{array}$ & 0 & $q_{\Delta}+\alpha N_{2}-c_{u}$ \\
$q_{2}+\alpha-c-c$
\end{tabular}

Table 1: Period 2 - Pricing Decision - Monopoly case

(i.e. $p \leq p_{o}$ ). Therefore, given the homogeneity of consumers, the incumbent charges $p_{o}$ to the $N_{2}$ consumers that are his only revenue source and extract their full surplus.

Monopolist does innovate. In this case, the new generation of the good with quality $q_{2}$ is produced by the monopolist. Under assumption 3 and the coordination assumption, it is optimal for the $N_{1}$ consumers to upgrade if the price charged is less or equal to the incremental surplus offered by the new good (i.e. $p \leq p_{u}$ ). Again, given consumer homogeneity, the monopolist charges $p_{u}$ to the $N_{1}$ consumers. Using similar arguments, it can be shown that the monopolists charges $p_{n}$ to the $N_{2}$ consumers. Note that innovation increase the source of revenues for the incumbent.

Table (1) summarizes the pricing decision by the monopolist in period 2 conditional on the outcome of the R\&D process. Each cell in the table shows the price charged to the $N_{1}$ and the $N_{2}$ consumers, respectively.

\subsubsection{First Period - Investment Decision}

Suppose that to obtain the improved quality in period 2, the monopolist has to invest and succeed according to the R\&D process described above. That is, the monopolist must decide the probability $s$ that in period 2 the innovation is achieved and the new generation of the good with quality $q_{2}$ is produced 21 The cost of choosing the probability $s$ is given by $C(s)=\frac{a s^{2}}{2}$, where $a$ represents a cost parameter. Assume that consumers coordinate on the Pareto-optimal equilibrium. Then, if the innovation is successful, for $q_{\Delta}+\alpha N_{2}-c_{u}>0$ (i.e. assumption 3 holds) in period 2 the $N_{1}$ consumers upgrade and pay a price $p_{u}$ and the $N_{2}$ consumers adopt the new good. If $q_{\Delta}+\alpha N_{2}-c_{u}<0$ (i.e. given that the innovation is achieved and assumption 3 does not hold) the $N_{1}$ consumers do not upgrade and the $N_{2}$ consumers adopt the new technology. If the innovation is not achieved, the $N_{1}$ consumers do not make any decision and the $N_{2}$ consumers adopt the old good. Consider the case where assumption 3 holds, then, the investment problem of

\footnotetext{
${ }^{21}$ Note that if the innovation can be achieved with certainty and at no cost, the analysis is the one presented in Ellison and Fudenberg (2000)
} 
the monopolist and the end of period 1 is given by

$$
\max _{s} \Pi_{M}=N_{1} p_{1}+s\left(N_{1} p_{u}+N_{2} p_{n}\right)+(1-s)\left(N_{2} p_{o}\right)-\frac{s^{2}}{2}
$$

with

$$
p_{1}=q_{1}+\alpha N_{1}-c+s\left(s_{n}-p_{u}\right)+(1-s)\left(s_{o}\right)
$$

In this expressions, we have simplified considering $a=1 p_{u}=q_{2}-q_{1}+\alpha N_{2}-c_{u}$, $p_{n}=q_{2}+\alpha-c, p_{o}=q_{1}+\alpha-c, s_{n}=q_{2}+\alpha-c_{u}$ and $s_{o}=q_{1}+\alpha$.

In this expression, $N_{1} p_{1}$ corresponds to the period 1 revenues, $s\left(N_{1} p_{u}+N_{2} p_{n}\right)+(1-$ $s)\left(N_{2} p_{o}\right)$ are the period 2 revenues and $\frac{s^{2}}{2}$ is the cost attached to the innovation process.

Consider the revenues obtained in period 1. As can be seen, $p_{1}$ extracts the full surplus enjoyed by the $N_{1}$. In particular, $q_{1}+\alpha N_{1}-c$ represents the period 1 surplus and $s\left(s_{n}-p_{u}\right)+(1-s)\left(s_{o}\right)$ is the expected period 2 surplus that is conditional on the outcome of the innovation. That is, with probability $s$ the innovation is achieved and, given assumption 3 holds, it is optimal for the $N_{1}$ consumers to upgrade in period 2 with a net surplus of $s_{n}-p_{u}$. On the other hand, if the innovation is not achieved, the period 2 net surplus of the $N_{1}$ consumers is equal to $s_{o}$.

Importantly, note that the price charged in period $1, p_{1}$, depends on the level of investment because the surplus that the $N_{1}$ consumers enjoy in period 2 is uncertain at the beginning of period 1. Moreover, observe that $\frac{\partial p_{1}}{\partial s}=-\alpha N_{2}<0$. This observation implies that through investment, the monopolist reduces the future value of its good sold in period 1. Therefore, a higher R\&D investment reduces the willingness to pay from the $N_{1}$ consumers in period 1 as the durability literature suggests. At the same time, a higher investment level increases the probability of introducing a new generation of the network good in period 2, and in consequence, expected period 2 revenues are increased. As we will see, it is the interaction (i.e. trade-off) between these two effects that represents the main impact of durability in the $\mathrm{R} \& \mathrm{D}$ incentives by the monopolist and highlights the role of commitment.

The revenues obtained in period 2 presented by the second and third term of equation (1) have a straightforward interpretation. In the following, we solve for the optimal investment decision given the problem stated in equation (1). We first present the no commitment case and then the commitment case. 


\subsubsection{No Commitment Case}

In the no commitment case the analysis of the SPNE rules out any non-credible threats by the monopolist. Therefore, consumers in period 1 determine their willingness to pay considering the case of what the monopolist would do after the $N_{1}$ consumers have made their period 1 purchasing decision. In other words, solving backwards and considering the $R \& D$ level that maximizes second period profits for the monopolist, we obtain the following first-order condition:

$$
0=N_{1} p_{u}+N_{2} p_{n}-N_{2} p_{o}-s^{n c}
$$

It can be seen that the second-order condition for an interior solution also holds. Thus, the corresponding optimal level of investment in the absence of commitment by the monopolist is given by

$$
s^{n c}=q_{\Delta}-N_{1} c_{u}+\alpha N_{1} N_{2}
$$

Before analyzing this result, we solve first for the commitment case.

\subsubsection{Commitment Case}

In this case, the monopolist is able to internalize the negative impact that his investment decision has on the first period prices (i.e. recall $\frac{\partial p_{1}}{\partial s}<0$ ). Therefore, by considering the $\mathrm{NE}$ of the global multi-stage game, we obtain the following first order condition:

$$
0=-N_{1} N_{2} \alpha+N_{1} p_{u}+N_{2} p_{n}-N_{2} p_{o}-s^{c}
$$

Analogously, the second-order condition for an interior solution holds and the optimal level of investment provided that the incumbent is able to commit is given by

$$
s^{c}=q_{\Delta}-N_{1} c_{u}
$$

As can be readily seen from the preceding analysis, $s^{n c}>s^{c}$ holds for any parameter configurations. This result is not surprising and is in line with the traditional literature. It says that without commitment, the monopolist has the incentive to invest more than in the presence of commitment because it does not internalize the negative impact of its investment level on the price charged in period 1. Moreover, it is evident that the 
difference between the two investment levels is equal to $\alpha N_{1} N_{2}$ which vanishes when the network externalities are not present (i.e. $\alpha=0$ ). This implies that the effect of commitment is completely isolated and will allow us to conclude that any inefficiency, if present, will be solely due to the presence of network externalities. ${ }^{22}$

This result is stated in the following proposition.

Proposition 1. Without the threat of entry, the monopolist invests more in the absence of commitment than it would be the case if commitment is possible. This difference is only due to the presence of network externalities.

In addition, comparing the two profit levels (solving for the corresponding optimal investment levels in equation (1) it can be shown that $\Pi_{M}^{c}-\Pi_{M}^{n c}=\frac{\left(N_{1}\right)^{2}\left(N_{2}\right)^{2} \alpha^{2}}{2}$ which is unambiguously positive. Again, this result highlights the main commitment problem on the R\&D incentives of a monopolist that arises in the presence of durable goods (see Waldman (1996)). That is, once a monopolist does not have the possibility to commit to future R\&D investments, its optimal decision affects negatively its overall profitability. Importantly, note that the previous result vanishes if $\alpha=0$.

In addition, given that consumers are homogeneous, the monopolist is able to extract all the surplus from the consumers and, therefore, the absence of commitment reduces social surplus.

Proposition 2. For the monopoly case, the absence of commitment in the RESD investment implies a lower social surplus compared to the case when commitment is possible. This result is only due to the presence of network externalities

The analysis of the monopoly model presented two main results. First, the presence of network externalities implies a commitment problem in the investment decision by the monopolists. This commitment problem is represented by an over-investment in the case of no commitment compared to the case where commitment is possible. And second, due to the presence of network externalities, the commitment problem implies a lower overall profit and an associated lower social welfare. These results are in line with the current literature and represent the benchmark for comparison for our analysis of entry.

\footnotetext{
${ }^{22}$ This result also holds in the Ellison and Fudenberg (2000) paper.
} 


\section{$3.2 \quad$ A Model with Entry}

In this subsection we extend the monopoly analysis presented above and consider the case of a potential entrant. Keeping the same framework, we model the case of an incumbent monopolist that serves the entire market in period 1 and must compete with a potential entrant in period 2. As explained before, entry is conditional on innovation and, therefore, both firms invest in developing a new technology at the end of period 1. At the beginning of period 2 the outcome of the innovation process is realized and price competition takes place.

As in the analysis of the monopoly case, the investment decision depends on the equilibrium concept adopted, namely, SPNE or NE, which characterizes the no commitment and commitment case, respectively. In order to proceed, we first solve for the period 2 demands, profits and price equilibria that follow from Bertrand competition. Then, we turn to the strategic investment decision at the end of period 1 and derive the commitment and the no commitment case.

\subsubsection{Second Period - Price Competition}

As in the monopoly analysis and in order to simplify exposition, we assume in what follows that assumption 3 holds. Note that price competition depends on the outcome of the innovation process, therefore, there are four cases to consider according to the success or failure of a given firm's innovation process, and the identity of that firm.

No firm innovates. In this case, no firm achieves the innovation. In consequence, the incumbent firm still produces the old good with quality $q_{1}$ in period 2 and the entrant firm has no production. As explained before, the $N_{1}$ consumers do not make any purchase decision (they already have the only existing good) and the $N_{2}$ consumers buy the old good if the price is less or equal to the total surplus they get from it. Therefore, the incumbent is able to charge $p_{o}$ to the $N_{2}$ consumers that are his only revenue source in period 2 . Note that this case, ex-post, is identical to the monopoly case without innovation.

Only Incumbent innovates. In this case, the new generation of the good is produced by the incumbent and the entrant does not enter the market. Therefore, given the assumption that the consumers are able to coordinate on the Pareto-Optimal equilibrium, the incumbent charges $p_{u}$ to the $N_{1}$ consumers and $p_{n}$ to the $N_{2}$ consumers. Note that innovation increases the source of revenues for the incumbent. Given that entry does not 


\begin{tabular}{|c|c|c|c|c|}
\hline Firm & $\begin{array}{c}\text { Both Firms } \\
\text { Innovate }\end{array}$ & $\begin{array}{c}\text { Incumbent } \\
\text { Innovates }\end{array}$ & $\begin{array}{c}\text { Entrant } \\
\text { Innovates }\end{array}$ & $\begin{array}{c}\text { No Firm } \\
\text { Innovates }\end{array}$ \\
\hline \hline Incumbent's & 0 & $q_{\Delta}+\alpha N_{2}-c_{u}$ & 0 & 0 \\
Prices & 0 & $q_{2}+\alpha-c$ & 0 & $q_{1}+\alpha-c$ \\
\hline Entrants's & 0 & 0 & $q_{\Delta}+\alpha N_{2}-c_{u}$ & 0 \\
Prices & 0 & 0 & $q_{2}+\alpha-c$ & 0 \\
\hline
\end{tabular}

Table 2: Period 2 - Price Competition - Entry case

take place, this case is, ex-post, identical to the monopoly case with successful innovation.

Only entrant innovates. In this case, the entrant innovates and is able to produce the new generation of the good in period 2. Therefore, the entrant firm is able to capture the $N_{2}$ consumers and charges $p_{n}$ to them. In addition, and assuming that he can identify the $N_{1}$ consumers (i.e. the entrant can offer a cross-subsidy), the price charged to them is $p_{u}$ subject to the coordination assumption discussed above ${ }^{23}$

Both firms innovate. In this case, both firms achieve the innovation and compete with homogeneous products in a homogeneous market. Thus, Bertrand competition drives prices and period 2 profits to zero.

Table (2) summarizes the pricing decision in period 2 conditional on the outcome of the R\&D process. Each cell in the table shows the price charged to the $N_{1}$ and the $N_{2}$ consumers, respectively.

\subsubsection{First Period - Investment Decisions}

After deriving the equilibrium prices from the competition in period 2 between the incumbent and the potential entrant, we are able to analyze the optimal investment decisions by the two firms. Note that in the case of the threat of entry, the investment decisions are derived strategically.

As explained before, the investment decisions correspond for the firms to choose the probability, $s_{k}$ for $k \in I, E$, that the innovation is achieved in period 2. In addition, there is cost $C\left(s_{k}\right)=\frac{a s_{k}^{2}}{2}$ associated with a given probability $s$, where $a$ corresponds to a cost parameter.

The overall problem of the incumbent firm is given by,

\footnotetext{
${ }^{23}$ Note that if the entrant cannot offer a cross-subsidy, the price charged to the $N_{1}$ is in any case equal to the incremental benefit that those consumer enjoy by purchasing the new good from the entrant firm.
} 


$$
\max _{s_{I}} \Pi_{I}=N_{1} p_{1}+s_{I}\left(1-s_{E}\right)\left(N_{1} p_{u}+N_{2} p_{n}\right)+\left(1-s_{I}\right)\left(1-s_{E}\right)\left(N_{2} p_{o}\right)-\frac{s_{I}^{2}}{2}
$$

with,

$$
p_{1}=q_{1}+\alpha N_{1}-c+s_{I}\left(1-s_{E}\right)\left(s_{n}-p_{u}\right)+\left(1-s_{I}\right)\left(1-s_{E}\right)\left(s_{o}\right)
$$

In this expressions, we have simplified considering $a=1 p_{u}=q_{2}-q_{1}+\alpha N_{2}-c_{u}$, $p_{n}=q_{2}+\alpha-c, p_{o}=q_{1}+\alpha-c, s_{n}=q_{2}+\alpha-c_{u}$ and $s_{o}=q_{1}+\alpha$.

In this expression, $N_{1} p_{1}$ corresponds to the period 1 revenues, $s_{I}\left(1-s_{E}\right)\left(N_{1} p_{u}+N_{2} p_{n}\right)$ are the period 2 revenues that can be obtained if the incumbent firm is the only innovator, $\left(1-s_{I}\right)\left(1-s_{E}\right)\left(N_{2} p_{o}\right)$ are the period 2 revenues for the case where no firm innovates, and $\frac{s_{I}^{2}}{2}$ is the cost attached to the innovation process. Recall that if the two firms innovate, profits are dissipated due to the price competition and that there is no revenues for the incumbent if the potential entrant is the unique innovator.

Consider the revenues obtained in period 1. As can be seen, $p_{1}$ extracts the full surplus enjoyed by $N_{1}$ by charging the total surplus enjoyed in period 1 (i.e. $q_{1}+\alpha N_{1}-c$ ) and the expected surplus enjoyed in period 2 (i.e. $s_{I}\left(1-s_{E}\right)\left(s_{n}-p_{u}\right)+\left(1-s_{I}\right)(1-$ $\left.s_{E}\left(s_{o}\right)\right)$. Moreover, as in the monopoly case, the period 1 price charged by the incumbent decreases with its own investment level. In particular, $\frac{\partial p_{1}}{\partial s_{I}}=-\alpha N_{2}\left(1-s_{E}\right)<0$. This observation implies that through a higher level of investment, the incumbent firm reduces the willingness to pay of the $N_{1}$ consumers in period 1 . At the same time, and similar to the monopoly case, higher investments boost period 2 revenues. However, investments in the context analyzed in this subsection play an additional role: deter entry. Therefore, we analyze not only the trade-off between more revenues in period 1 or 2 , but also consider the preemptive role of investments.

Analogously, the problem of the entrant firm is given by,

$$
\max _{s_{E}} \Pi_{E}=s_{E}\left(1-s_{I}\right)\left(N_{1} p_{u}+N_{2} p_{n}\right)-\frac{s_{E}^{2}}{2}
$$

Again, we have simplified using $a=1 p_{u}=q_{2}-q_{1}+\alpha N_{2}-c_{u}, p_{n}=q_{2}+\alpha-c, p_{o}=q_{1}+$ $\alpha-c, s_{n}=q_{2}+\alpha-c_{u}$ and $s_{o}=q_{1}+\alpha$. Note that the entrant can only have positive revenues if it is the unique innovator. In addition, it is important to highlight that the fact that 
the potential entrant has no period 1 revenues, it will not face any commitment problem. However, given that the investment levels are obtained strategically, the behavior of the incumbent has an important impact on the behavior of the potential entrant.

\subsubsection{No Commitment Case}

As in the monopolist problem, this case is obtained by focusing on the SPNE. Accordingly, the first-order condition for the incumbent firm taking into account only second period profits is given by,

$$
0=\left(1-s_{E}\right)\left(N_{1} p_{u}+N_{2} p_{n}\right)-\left(1-s_{E}\right)\left(N_{2} p_{o}\right)-s_{I}^{n c}
$$

Considering equation (5), the SPNE concept provides the first-order condition for the entrant firm given by,

$$
0=\left(1-s_{I}\right)\left(N_{1} p_{u}+N_{2} p_{n}\right)-s_{E}^{n c}
$$

It can be seen that the second-order conditions for an interior solution are satisfied. Thus, solving equations (6) and (7) provides the equilibrium $R \& D$ levels for the incumbent and the entrant firm in the absence of commitment by the incumbent firm. Again, note that given that the entrant firm only competes in period 2 , it has no choice concerning a committed action. Before analyzing the results, we calculate first the commitment case.

\subsubsection{Commitment Case}

As should be clear by now, the NE of the global game represents the commitment solution and provides the following first-order condition for the investment level by the incumbent. That is,

$$
\begin{aligned}
0= & N_{1}\left(\left(1-s_{E}\right)\left(s_{n}-p_{u}\right)-\left(1-s_{E}\right)\left(s_{o}\right)\right) \\
& +\left(1-s_{E}\right)\left(N_{1} p_{u}+N_{2} p_{n}\right)-\left(1-s_{E}\right)\left(N_{2} p_{o}\right)-s_{I}^{c}
\end{aligned}
$$

Analogously, the first-order condition for the entrant firm is,

$$
0=\left(1-s_{I}\right)\left(N_{1} p_{u}+N_{2} p_{n}\right)-s_{E}^{c}
$$


As in the case of no commitment, solving equations (8) and (9) provides the equilibrium investment levels for both firm in the presence of commitment of the incumbent firm. In order to simplify the analysis (given the large number of parameters), we consider the behavior of the best response functions described by the first order conditions. Given the specifications on the R\&D processes, from observations of equations (6) and (7) for the no commitment case, and equations (8) and (9) for the commitment case, the best response functions are linear and therefore provide a unique equilibrium. Moreover, they are downward sloping implying strategic substitutability in the investment levels. We require and additional assumption to guarantee the existence of an economically plausible equilibrium.

Assumption 4. $q_{2}<1+c_{u}-\alpha$. The best response functions that describe the incentives to innovate are stable.

As can be seen, assumption 4 restricts the size of the innovation. This assumption guarantees, in addition to provide stability to the best response functions, that for any parameter configurations, the probabilities of success lie on the interval $(0,1)$. Figure 1 shows the behavior of the best response functions and suffices to provide the main results.

As can be seen from the figure, $R_{E}\left(s_{I}\right)$ represents the best respond function for the entrant as a function of the investment level of the incumbent firm. This function is obtained from solving equation (7) for $s_{E}^{n c}{ }^{24}$ Equivalently, the best respond functions for the incumbent firm, $R_{I n c}\left(s_{E}\right)$ and $R_{I c}\left(s_{E}\right)$, are obtained from solving equations (6) and (8) for $s_{I}^{n c}$ and $s_{I}^{c}$, respectively. It can be shown that under assumption 4 the best response functions lie always on the positive quadrant and below 1 .

In particular, the analysis of the market outcome is summarized in Figure 1. Figure 1a shows the case where network externalities are present and Figure 1b shows the case without network externalities. Figure 1a shows two main results. First, independent of the presence of commitment, the potential entrant always invests more than the incumbent firm. That is, in any case the equilibrium lies below the 45 degree line. Second, as explained above, in the absence of commitment, the incumbent firm does not internalize the negative effect that its own investment has on his first period price and, therefore, invest more than it would be the case if commitment is possible. As a consequence, once commitment is considered the incumbent corrects its R\&D expenditures negatively. This

\footnotetext{
${ }^{24}$ Note that the form of $R_{E}\left(s_{I}\right)$ does not depend on the presence of commitment because the entrant only competes in period 2 . Therefore, $R_{E}\left(s_{I}\right)$ can also be obtained from solving equation $(9)$ for $s_{E}^{c}$.
} 
correction implies a stronger incentive for the entrant to innovate and, hence, increases the entrant's level of investment. In Figure 1 this is represented through the fact that the commitment equilibrium lies below and to the right of the no commitment equilibrium. This result holds for any parameter configuration satisfying the assumptions of the model.

Proposition 3. Independent of the possibility of commitment by the incumbent, the potential entrant always invests in RED more than the incumbent firm. Moreover, this difference is increased if commitment is possible.

In addition, from equations (6) and (8) it can be shown that the difference between the commitment and no commitment case is only due to the presence of network externalities. This is represented in Figure 1 by the fact that the difference between the best response function of the incumbent without commitment lies above the best response function in the presence of commitment. In particular, the difference between the points at which both lines intersect the vertical axis is always positive and equal to $\alpha N_{1} N_{2}$. Therefore, the strategic impact of entry is completely isolated. Figure (1b) shows a particular case with $\alpha=0$.

Proposition 4. The difference in the optimal investment levels with or without commitment is only due to the presence of network externalities.

Importantly, several numerical analyses suggest that, for some parameter configurations, the profit of the incumbent is higher in the absence of commitment than it would be the case if commitment is possible. That is, the threat of entry implies that in some special cases it is strategically optimal for the incumbent to increase its R\&D investment as a mechanism to response to the potential entrant. This result is in clear contrast with the monopoly analysis presented before and, therefore, extends the analysis of Ellison and Fudenberg (2000).

The result that the threat of entry may eliminate the commitment problem of a monopolist in durable goods market has been analyzed by Bucovetsky and Chilton (1986), Ausubel and Deckenere (1986) and Vettas (2001). However, to the best of our knowledge, there is no analysis that considers the role of R\&D incentives in this situation and, therefore, our result differs from the current literature.

Proposition 5. With the threat of entry, the incumbent firm may achieve a higher profit by strategically not committing its investment level. This is in contrast to the case without the threat of entry. 
Figure 1a

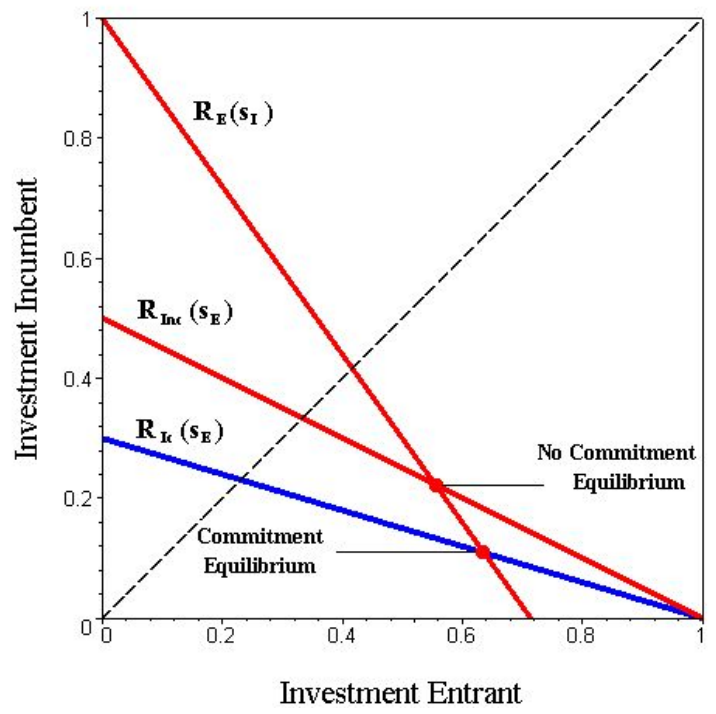

Figure $1 \mathrm{~b}$ (no network ext.)

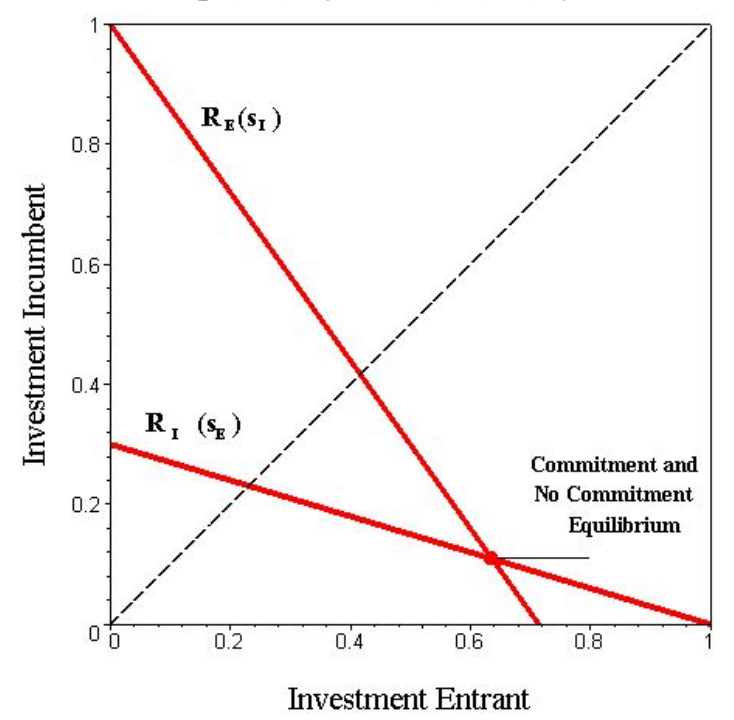

Figure 1: Best Response Functions - Market Outcome

One of the main objectives of this paper is to analyze the social efficiency of the incentives to innovate in the presence of network externalities and durable goods. This is the purpose of the next section.

\section{Social Optimum}

In the previous section we obtained the incentives to innovate in an industry that exhibits network externalities and durable goods. In particular, we considered the monopoly case and concluded that, in line with the current literature, in the absence of commitment the monopolist has incentive to invest in $R \& D$ in excess of what it would maximize its overall profits. Moreover, we showed that the negative impact of this over-investment was reflected in lower social welfare and it was a consequence of the presence of network externalities.

Subsequently, we analyzed the case where the monopolist is faced by a potential entrant. Interestingly, we were able to conclude that due to the threat of entry, the commitment problem exhibited in the monopoly case by the incumbent firm was not present anymore. Even though the absence of commitment was reflected in higher investments because the incumbent is not able to internalize the negative impact on his period 1 pricing, the threat of entry, and the induced higher level of investment, more than compensated 
the lower period 1 revenues by increasing the expected period 2 profits.

However, it is important to analyze the social efficiency of the results obtained in the previous section. Therefore, and as a major objective of this paper, the present section considers the problem faced by a social planner that maximizes social surplus. In particular, we obtain the socially optimal R\&D incentives and compare our results with the ones obtained before for the case of the market outcome. Moreover, we investigate the role of network externalities in the potential social inefficiencies that may arise.

Assuming that the social planner is able to produce the two goods, set prices equal to zero, induce adoption and invest in $\mathrm{R} \& \mathrm{D}$, its problem can be written as

$$
\begin{aligned}
\max _{s_{I}, s_{E}} W= & N_{1} p_{1}^{s}+s_{I} s_{E}\left(N_{1} s_{n}+N_{2} p_{n}\right) s_{I}\left(1-s_{E}\right)\left(N_{1} s_{n}+N_{2} p_{n}\right) \\
& +s_{I}\left(1-s_{E}\right)\left(N_{1} s_{n}+N_{2} p_{n}\right)+\left(1-s_{I}\right)\left(1-s_{E}\right)\left(N_{1} s_{o}+N_{2} p_{o}\right) \\
& -\frac{s_{I}^{2}}{2}-\frac{s_{E}^{2}}{2}
\end{aligned}
$$

with

$$
p_{1}^{s}=q_{1}+\alpha N_{1}-c
$$

As before, we have simplified taking into account $a=1 p_{u}=q_{2}-q_{1}+\alpha N_{2}-c_{u}$, $p_{n}=q_{2}+\alpha-c, p_{o}=q_{1}+\alpha-c, s_{n}=q_{2}+\alpha-c_{u}$ and $s_{o}=q_{1}+\alpha$.

Equation 10 is obtained by calculating, for each period, the maximum social surplus that can be enjoyed by the entire population given that the social planner can induce adoption. In addition, the assumption that the social planner invests in the two technologies simply reflects a risk diversification strategy. That is, ex-ante, it is impossible for the social planner to realize which technology will be successful in period 2. Also, note that investing in both technologies is an efficient strategy given the quadratic form of the costs associated with the innovation process.

Note that for the social planner problem the SPNE and the NE coincide. Therefore, we can calculate the first-order conditions that provide the socially optimal investment level. This expressions are,

$$
0=\left(1-s_{E}\right)\left(N_{1} s_{n}+N_{2} p_{n}\right)-\left(1-s_{E}\right)\left(N_{1} s_{o}+N_{2} p_{o}\right)-s_{I}^{w}
$$




$$
0=\left(1-s_{I}\right)\left(N_{1} s_{n}+N_{2} p_{n}\right)-\left(1-s_{I}\right)\left(N_{1} s_{o}+N_{2} p_{o}\right)-s_{E}^{w}
$$

As can be seen from equations (11) and (12), the social planner invests equally in both technologies. This is due to the fact that the social planner internalizes the costs of the projects. Moreover, straightforward algebra from equations (11) and (8) shows that the best response function of the social planner is identical to the one exhibit by the incumbent firm in the presence of commitment. This implies that in order to compare the social optimum with the results from the market outcome we should consider the results presented in Figure 1 with the level of investment produced by the incumbent's best response function in the presence of commitment. Given that the social planner invests equally in both technologies, the social optimal level of investments is reached in the intersection of the incumbent's best response function with commitment and the 45 degree line. This is presented in Figure 2 .

Figure 2 provides two interesting results. First, it shows that the entrant firm, unambiguously, always over-invests in R\&D in relation to the socially optimal amount. That is, independent of the presence of commitment by the incumbent, the market equilibrium always lie to the right of the social optimum. This result is due to the fact that a successful innovation represents the only possibility for the potential entrant to make positive profits.

Proposition 6. The potential entrant unambiguously exhibits an over-investment in comparison with the social optimum. This result is independent of the possibility of commitment by the incumbent firm.

In addition, it can be observed in Figure 2 that in the absence of network externalities or for sufficiently low values of $\alpha$ the incumbent firm always under-invests in R\&D. However, depending on the extent of the network externalities (i.e the value of $\alpha$ ) the incumbent firm may exhibit a lower (Figure 2a), equal (Figure 2b) or higher (Figure 2c) level of investment compared with the social optimum. This result follows from numerical simulations.

Proposition 7. Depending on the extent of the network externalities, the incumbent firm may exhibit a lower, equal or higher investment level in comparison with the social optimum. 
Figure 2a

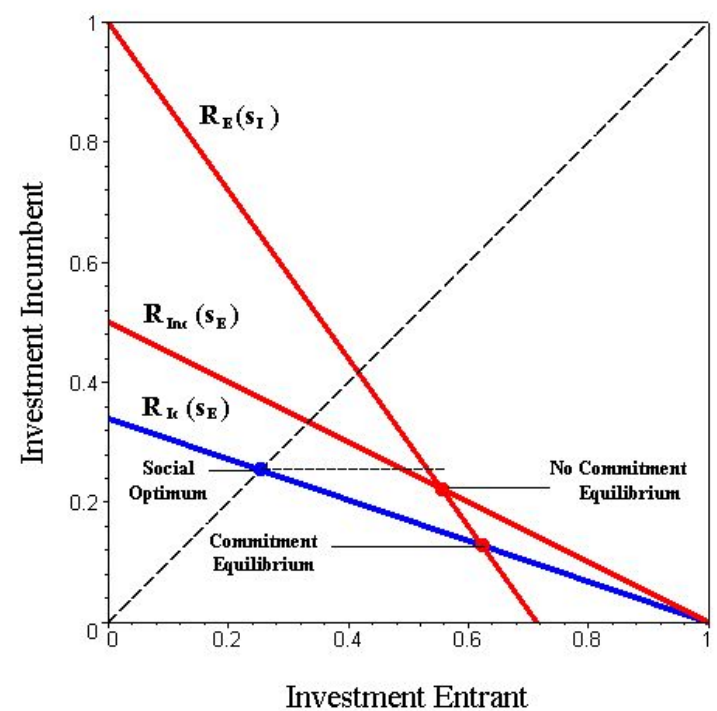

Figure $2 b$

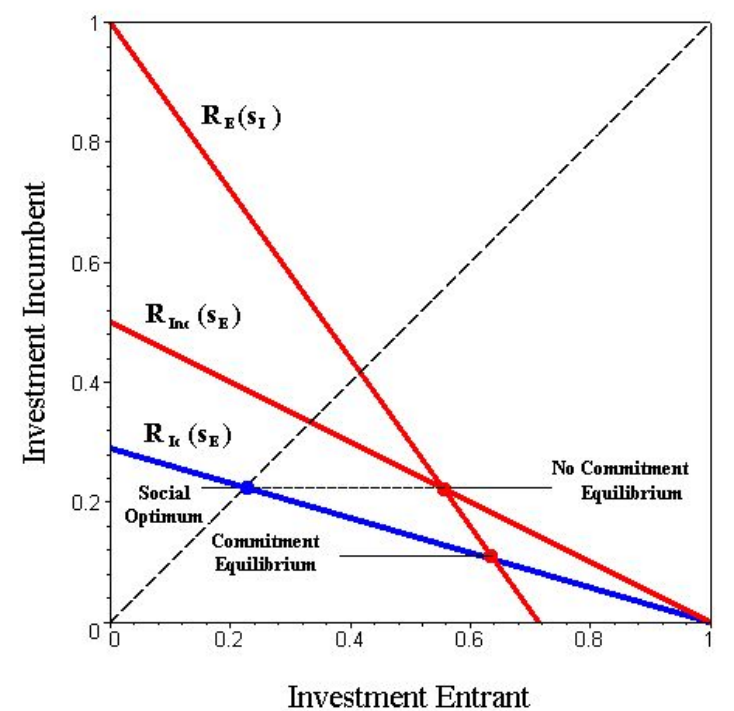

Figure 2c

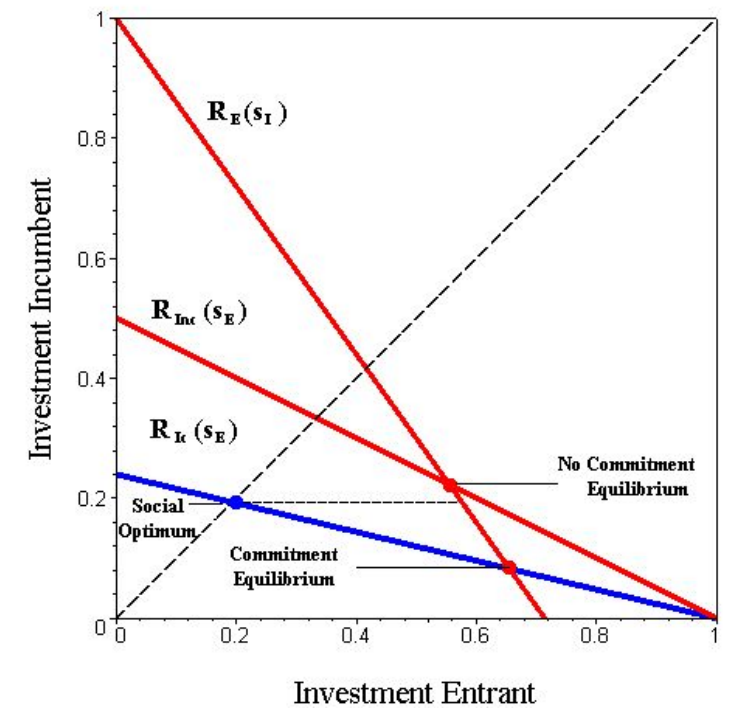

Figure 2: Best Response Fncs. - Social Optimum 
This result sheds some light on the controversy around the efficiency of the observed market structure in network industries. As has been pointed out in the literature (and observed in reality), network industries are characterized by the presence of few successful incumbents. This observed structure has led regulation authorities to consider whether the high level of concentration is detrimental for the socially optimal level of innovation undertaken in these industries. Our analysis shows that there is no clear answer to that questions and that the measurement of the extent of network externalities may be crucial for policy purposes. Hence, any conclusion must be based on a formal analysis and this paper is a small step in that direction.

\section{Conclusions}

We presented a model of $R \& D$ competition between an incumbent and a potential entrant in a market with durable goods and network externalities. In particular, we analyzed the market outcome and the social efficiency of the incentive to innovate in the presence of uncertain innovation processes. The robustness of the presented results with respect to the assumed functional forms is the objective of current work.

We found three main results. First, the threat of entry reverses the commitment problem that a monopolist (without such threat) may face in its $R \& D$ decision given the durability of the network goods. This result is not present in the current literature on $R \& D$ and follows from the role that $R \& D$ incentives play in deterring entry. In our case, the monopolist's commitment problem arises only due to the presence of network externalities.

Second, the levels of $R \& D$ determined by market outcome might differ from the socially optimal levels. In particular, a potential entrant always over-invests (as an entry strategy) and an established incumbent might exhibit higher, lower or equal R\&D levels in comparison with the social optimum. This result suggests that successful entry takes place too often in comparison with the social optimum.

And third, the extent of network externalities is the crucial parameter in the efficiency of the incumbent $R \& D$ level. In fact, it is only the presence of network externalities that permits, potentially, to the established incumbent to provide an efficient level of innovation. Without network externalities (or very low network effects), it is shown that the incumbent firm always under-invests in R\&D efforts. This result sheds some light 
on the debate whether a dominant incumbent in a network industry provides sufficient innovation to the society.

We recognize several areas of further research in the area of $R \& D$ incentives in the presence of network externalities and durable goods. To reduce the dependence on initial conditions and parameter assumptions, a fully dynamic model may shed light on some more realistic characteristics of industry evolution inside the framework analyzed in current paper. In addition, the analysis of compatibility decisions may also be considered given its obvious relevance in these industries but is for the time being beyond the scope of the present paper. Finally, a more detailed (or alternative) description of the consumers' coordination assumptions may enrich the results. 


\section{References}

Ausubel, and Deckenere, (1987), "One is Almost Enough for Competition", RAND Journal of Economics, 18, 255-274.

Bagnoli, M., S. Salant, and J., Swierzbinski (1989), "Durable-goods Monopoly with Discrete Demand", Journal of Political Economy, 97, 1459-1478.

Bensaid, B., and Lesne, J.P., (1996), "Dynamic Monopoly Pricing with Network Externalities", International Journal of Industrial Organization, 14, 837-855.

Besen, S. and J. Farrell, (1994), "Choosing How to Compete: Strategies and Tactics in Standardization", Journal of Economic Perspectives, vol. 8, pp. 117-131.

De Bijil, P.W.J. and S. Goyal, (1995), "Technological Change in Markets with Network Externalities", International of Industrial Organization, 13, 307-325.

Bucovetsky, S. and J. Chilton, (1986), "Concurring Renting and Selling in a Durable Goods Monopoly under Threat of Entry", RAND Journal of Economics, 17, 261275 .

Bulow, J., (1982), "Durable Goods Monopolists", Journal of Political Economy, 15, 314-332.

Bulow, J., (1986), "An Economic Theory of Planned Obsolescence", Quarterly Journal of Economics, 101, 729-749.

Cabral, L.M.B., D. Salant, and G. Woroch, (1999), "Monopoly Pricing with Network Externalities", International Journal of Industrial Organization, 17, 199-214.

Coase, R., (1972), "Durability and Monopoly", Journal of Law and Economics, 15, 143143.

Choi, J.P., (1994), "Network Externalities, Compatibility Choice, and Planned Obsolescence", Journal of Industrial Economics, 42, 167-182.

Ellison, G., and D. Fudenberg, (2000), "The Neo-Luddite's Lament: Excessive Upgrades in the Software Industry", RAND Journal of Economics, 31, 253-272. 
Farrell, J. and M. Katz, (2005), "Competition or Predation? Consumer Coordination, Strategic Pricing and Price Floors in Network Markets", Journal of Industrial Economics, LIII, 203-231.

Farrell, J. and G. Saloner, (1985), "Standardization, Compatibility and Innovation", Rand Journal of Economics, vol. 16, 70-83.

Farrell, J. and G. Saloner, (1986), "Installed Base and Compatibility: Innovation, Product Preannouncement, and Predation", American Economic Review, 76, 940-955.

Fudenberg, D. and J. Tirole, (1998), "Upgrades, Tradeins, and Buybacks", RAND Journal of Economics, 29, 235-258.

Fudenberg, D. and J. Tirole, (2000), "Pricing a Network Good to Deter Entry", Journal of Industrial Economics, XLVIII, 373-390.

Grout, P.A., and I. Park, (2005), "Competitive Planned Obsolescence", RAND Journal of Economics, 36, 696-612.

Gul, F., H. Sonnenschein, and R. Wilson, (1986), "Foundations of Dynamic Monopoly and the Coase Conjecture", Journal of Economic Theory, 39, 155-190.

Hendel, I., and A. Lizzeri, (1999), "Adverse Selection in Durable Goods Markets", American Economic Review, 89, 1097-1115.

Kahn, C. M., (1986), "The Durable Goods Monopolist and Consistency with Increasing Costs", Econometrica, 54, 275-294.

Katz, M. and C. Shapiro, (1985), "Network Externalities, Competition and Compatibility", American Economic Review, vol. 75, 424-440.

Katz, M. and C. Shapiro, (1986), "Technology Adoption in the Presence of Network Externalities", Journal of Political Economy, 94, 822-84.

Katz, M. and C. Shapiro, (1992), "Product Introduction with Network Externalities", Journal of Industrial Economics, 40, 55-84.

Katz, M. and C. Shapiro, (1994), "Systems Competition and Network Effects", Journal of Economic Perspectives, vol. 8, pp. 93-115. 
Kristiansen, E.G., (1996), "R\&D in Markets with Network Externalities, International Journal of Industrial Organization, Vol. 14, pp. 769-784.

Mason, R., (2000), "Network Externalities and the Coase Conjecture", European Economic Review, 44, 1981-1992.

Reinganum, J., (1989), "The Timing of Innovation: Research, development and diffusion". In R. Schmalensee and R. Willig, (eds.) (1989). Handbook of Industrial Organization, North-Holland. 849-908.

Shapiro, C. and H. Varian, (1999). Information Rules: A strategic guide to the network economy. Harvard Business School Press.

Stokey, N., (1981), "Rational Expectations and Durable Goods Pricing", Bell Journal of Economics, 12, 112-128.

Waldman, M., (1993), "A New Perspective on Planned Obsolescence", Quarterly Journal of Economics, 108, 273-283.

Waldman, M., (1996), "Planned Obsolescence and the R\&D Decision", RAND Journal of Economics, 27, 583-595.

Waldman, M., (1997), "Eliminating the Market for Secondhand Goods: An Alternative Explanation for Leasing", Journal of Law and Economics, 40, 61-92.

Waldman, M., (2003), "Durable Goods Theory for Real World Markets", Journal of Economic Perspectives, 17, 131-154. 